Research Article

\title{
Multiattribute Decision-Making Problems in terms of the Weighted Mean Operation of Two Aggregation Operators of Orthopair Z-Numbers
}

\author{
Mailing Zhao' ${ }^{1}$ and Jun Ye ${ }^{1,2}$ \\ ${ }^{1}$ Department of Electrical Engineering and Automation, Shaoxing University, Shaoxing 312000, China \\ ${ }^{2}$ School of Civil and Environmental Engineering, Ningbo University, Ningbo 315211, China \\ Correspondence should be addressed to Jun Ye; yejun1@nbu.edu.cn
}

Received 16 August 2021; Revised 7 September 2021; Accepted 20 September 2021; Published 4 October 2021

Academic Editor: Feng Feng

Copyright (c) 2021 Mailing Zhao and Jun Ye. This is an open access article distributed under the Creative Commons Attribution License, which permits unrestricted use, distribution, and reproduction in any medium, provided the original work is properly cited.

The $Z$ number defined by Zadeh can depict the fuzzy restriction/value and reliability measure by an ordered pair of fuzzy values to strengthen the reliability of the fuzzy restriction/value. However, there exist truth and falsehood $Z$-numbers in real life. Thus, the $Z$ number cannot reflect both. To indicate both, this study presents an orthopair $Z$-number (OZN) set to depict truth and falsehood values (intuitionistic fuzzy values) and their reliability levels in uncertain and incomplete cases. Next, we define the operations, score and accuracy functions, and sorting rules of OZNs. Further, the OZN weighted arithmetic mean (OZNWAM) and OZN weighted geometric mean (OZNWGM) operators are proposed based on the operations of OZNs. According to the weighted mean operation of the OZNWAM and OZNWGM operators, a multiattribute decision-making (MADM) model is established in the case of OZNs. Lastly, a numerical example is presented to reflect the flexibility and rationality of the presented MADM model. Comparative analysis indicates that the presented MADM model can indicate its superiority in the reliability and flexibility of decision results. Meanwhile, the resulting advantage of this study is that the presented MADM model can strengthen the reliability level of orthopair fuzzy values and make the decision results more reliable and flexible.

\section{Introduction}

In the case of fuzzy decision, fuzzy information expression and aggregation are two key issues. Then, a fuzzy set [1] only contains a truth-membership degree, but lacks a falsehoodmembership degree. To make up for this issue, Atanassov [2] defined an intuitionistic fuzzy set (IFS) that contains truthand falsehood-membership degrees. After that, some researchers proposed the weighted arithmetic and geometric mean operators of intuitionistic fuzzy values (IFVs) $[3,4]$ and utilized them in multiattribute decision-making (MADM), while other researchers further put forward different aggregation operators of IFVs [5-15] for MADM. Then, the truth- and falsehood-membership degrees in IFV are also named as an orthopair fuzzy value (OFV). However, the sum of the truth- and falsehood-membership degrees may be more than one in some cases. To represent such an
OFV, some researchers defined Pythagorean fuzzy sets (PFSs) $[16,17]$ and Pythagorean fuzzy aggregation algorithms [18-23] for MADM. Then, other researchers also introduced a hybrid method of PFSs for MADM [24] and a digraph and matrix approach for risk evaluations [25]. As the generalization of PFSs, the notion of generalized OFVs [26-28] was introduced to flexibly present the hybrid information range of the truth- and falsehood-membership degrees regarding different values of the parameter $q$. Then, some aggregation operators of $q$-rung orthopair fuzzy sets/ values ( $q$-ROFSs/ $q$-ROFVs) [29-31] were presented and applied in MADM. In the case of interval-valued $q$-rung orthopair dual-hesitant fuzzy sets, interval-valued $q$-rung orthopair dual-hesitant fuzzy Hamacher graphs were introduced for MADM [32]. Under the indeterminate case of the truth- and falsehood-membership degrees, Ye et al. [33] defined an orthopair indeterminate set/value (OIS/OIV) and 
some aggregation operators of OIVs and then established an orthopair indeterminate MADM model with indeterminate ranges/risks of decision makers (DMs) in the case of OISs.

However, IFV, OFV, $q$-ROFV, and OIV cannot contain their reliability measures/levels. Then, both a fuzzy value (fuzzy constraint) and a reliability level contained in the $Z$-number (ZN) defined by Zadeh [34] are described by an ordered pair of fuzzy values in vague and uncertain cases. Clearly, ZN demonstrates its more reliable superiority over the classical fuzzy value. Therefore, $\mathrm{ZNs}$ have been used for some applications [35-37]. Although ZN implies the aforementioned superiority, it cannot reflect the truth and falsehood ZNs in real problems. Furthermore, the existing IFV, OFV, $q$-ROFV, and OIV cannot reflect the truth and falsehood ZNs due to the lack of their reliability measures. In this case, it is important we need to strengthen the reliability measure of IFV and to propose an orthopair $Z$-number (OZN) set for making up for the defect of the existing IFV/ OFV. Motivated based on the idea of the truth and falsehood $\mathrm{ZNs}$, this study proposes an orthopair Z-number (OZN) set to depict the truth and falsehood $\mathrm{ZNs}$ in uncertain and vague cases. Then, we define the operations and score and accuracy functions of OZNs and propose the OZN weighted arithmetic mean (OZNWAM) and OZN weighted geometric mean (OZNWGM) operators. Since the OZNWAM operator tends to group arguments and the OZNWGM operator tends to personal arguments, we can propose the weighted mean operation of the OZNWAM and OZNWGM operators to overcome both prejudices. According to the weighted mean operation of the two operators, a MADM model is established in the case of OZNs. A numerical example is presented to reflect the flexibility and rationality of the presented MADM model. Compared to existing related MADM models, the superiority of this study is that the presented MADM model can strengthen the reliability level of OFVs and make the decision results more reliable and flexible.

The rest of this article contains the following parts: Section 2 presents an OZN set and the operations, score and accuracy functions, and sorting rules of OZNs. Then, the OZNWAM and NZNWGM operators and their properties are presented in Section 3. In Section 4, a MADM model is established by using the weighted mean operation of the OZNWAM and OZNWGM operators. In Section 5, an illustrative example and comparative analysis are presented to demonstrate the flexibility and rationality of the presented MADM model in the case of OZNs. Lastly, this paper addresses some conclusions and further study in Section 6.

\section{Orthopair Z-Number Sets}

Inspired by the notion of ZNs [34], this section proposes the definition of an OZN set by a pair of truth and falsehood ZNs.

Definition 1. Set $Y$ as a universe set. Then, an OZN set in $Y$ is defined below:

$$
Z_{O Z N}=\{\langle y, T(P, Q)(y), F(P, Q)(y)\rangle \mid y \in Y\},
$$

where $T(P, Q)(y)=(T P(y), T Q(y)): Y \longrightarrow[0,1]^{2}$ and $F(P$, $Q)(y)=(F P(y), F Q(y)): Y \longrightarrow[0,1]^{2}$ are the truth and falsehood ZNs. In $T(P, Q)(y)$ and $F(P, Q)(y), P$ is OFVs/IFVs for $y \in Y$, such that the condition $0 \leq T P(y)+F Q(y) \leq 1$; then, $Q$ is the reliability measures of the truth and falsehood fuzzy values for $P$.

Then, the simplified form of the element $\langle y, T(P, Q)(y), F(P, Q)(y)\rangle$ in $Z_{O Z N}$ is represented by $z_{\text {OZN }}=\langle T(P, Q), F(P, Q)\rangle=\langle(T P, T Q),(F P, F Q)\rangle$, which is named OZN or an intuitionistic ZN (IZN).

Definition 2. Let $z_{\mathrm{OZN} 1}=\left\langle T_{1}(P, Q), F_{1}(P, Q)\right\rangle=\left\langle\left(T P_{1}, T\right.\right.$ $\left.\left.Q_{1}\right),\left(F P_{1}, F Q_{1}\right)\right\rangle$ and $z_{O Z N 2}=\left\langle T_{2}(P, Q), F_{2}(P, Q)\right\rangle=\langle$ $\left.\left(T P_{2}, T Q_{2}\right),\left(F P_{2}, F Q_{2}\right)\right\rangle$ be two OZNs and $\alpha>0$. Thus, their operations are defined below:

(1) $z_{\mathrm{OZN} 1} \supseteq z_{\mathrm{OZN} 2} \Longleftrightarrow T P_{1} \geq T P_{2}, T Q_{1} \geq T Q_{2}, F P_{1} \leq F P_{2}$, and $F Q_{1} \leq F Q_{2}$

(2) $z_{\mathrm{OZN} 1}=z_{\mathrm{OZN} 2} \Longleftrightarrow z_{\mathrm{OZN1}} \supseteq z_{\mathrm{OZN} 2}$ and $z_{\mathrm{OZN} 2} \supseteq z_{\mathrm{OZN} 1}$

(3) $z_{\mathrm{OZN1}} \cup z_{\mathrm{OZN2} 2}=\left\langle\left(T P_{1} \vee T P_{2}, T Q_{1} \vee T Q_{2}\right),\left(F P_{1} \wedge\right.\right.$ $\left.\left.F P_{2}, F Q_{1} \wedge F Q_{2}\right)\right\rangle$

(4) $z_{\mathrm{OZN} 1} \cap z_{\mathrm{OZN} 2}=\left\langle\left(T P_{1} \wedge T P_{2}, T Q_{1} \wedge T Q_{2}\right), \quad\left(F P_{1} \vee\right.\right.$ $\left.\left.F P_{2}, F Q_{1} \vee F Q_{2}\right)\right\rangle$

(5) $\left(z_{O Z N 1}\right)^{c}=\left\langle\left(F P_{1}, F Q_{1}\right),\left(T P_{1}, T Q_{1}\right)\right\rangle$ (complement of $\left.z_{\mathrm{OZN1}}\right)$

(6) $z_{\mathrm{OZN} 1} \oplus z_{\mathrm{OZN} 2}=\left\langle\left(T P_{1}+T P_{2}-T P_{1} \cdot T P_{2}, T Q_{1}+T Q_{2}\right.\right.$ $\left.\left.-T Q_{1} \cdot T Q_{2}\right),\left(F P_{1} \cdot F P_{2}, F Q_{1} \cdot F Q_{2}\right)\right\rangle$

(7) $z_{\mathrm{OZN1}} \otimes z_{\mathrm{OZN1}}=\left\langle\left(T P_{1} \cdot T P_{2}, T Q_{1} \cdot T Q_{2}\right),\left(F P_{1}+F P_{2}\right.\right.$ $\left.\left.-F P_{1} \cdot F P_{2}, F Q_{1}+F Q_{2}-F Q_{1} \cdot F Q_{2}\right)\right\rangle$

(8) $\alpha \cdot z_{\text {OZN1 }}=\left\langle\left(1-\left(1-T P_{1}\right)^{\alpha}, 1-\left(1-T Q_{1}\right)^{\alpha}\right),\left(F P_{1}^{\alpha}\right.\right.$, $\left.\left.F Q_{1}^{\alpha}\right)\right\rangle$

(9) $z_{\mathrm{OZN1}}^{\alpha}=\left\langle\left(T P_{1}^{\alpha}, T Q_{1}^{\alpha}\right),\left(1-\left(1-F P_{1}\right)^{\alpha}, 1-\left(1-F Q_{1}\right)^{\alpha}\right)\right\rangle$

To sort OZNs $z_{\mathrm{OZN} i}=\left\langle T_{i}(P, Q), F_{i}(P, Q)\right\rangle=\left\langle\left(T P_{i}, T Q_{i}\right)\right.$, $\left.\left(F P_{i}, F Q_{i}\right)\right\rangle(i=1,2)$, the score and accuracy functions of OZNs are introduced, respectively, below:

$$
\begin{aligned}
& C\left(z_{\mathrm{OZN} i}\right)=T P_{i} \cdot T Q_{i}-F P_{i} \cdot F Q_{i} \text { for } C\left(z_{\mathrm{OZN} i}\right) \in[-1,1], \\
& E\left(z_{\mathrm{OZN} i}\right)=T P_{i} \cdot T Q_{i}+F P_{i} \cdot F Q_{i} \text { for } E\left(z_{\mathrm{OZNi}}\right) \in[0,1] .
\end{aligned}
$$

Thus, we can give the following sorting rules of the two OZNs:

(1) If $C\left(z_{\mathrm{OZN} 1}\right)>C\left(z_{\mathrm{OZN} 2}\right)$, then $z_{\mathrm{OZN} 1}>z_{\mathrm{OZN} 2}$

(2) If $C\left(z_{\mathrm{OZN} 1}\right)=C\left(z_{\mathrm{OZN} 2}\right)$ and $E\left(z_{\mathrm{OZN} 1}\right)>E\left(z_{\mathrm{OZN} 2}\right)$, then $z_{\mathrm{OZN} 1}>z_{\mathrm{OZN} 2}$

(3) If $C\left(z_{\mathrm{OZN} 1}\right)=C\left(z_{\mathrm{OZN} 2}\right)$ and $E\left(z_{\mathrm{OZN} 1}\right)=E\left(z_{\mathrm{OZN} 2}\right)$, then $z_{\mathrm{OZN} 1}=z_{\mathrm{OZN} 2}$

Example 1. Set two OZNs as $z_{\mathrm{OZN} 1} \leq(0.8,0.8),(0.1,0.8)>$ and $z_{\mathrm{OZN} 2} \leq(0.7,0.9),(0.2,0.8)>$. Thus, the sorting of both is yielded as follows: 
Using equation (2), we have $C\left(z_{\mathrm{OZN} 1}\right)=0.8 \times 0.8-0.1 \times$ $0.8=0.56$ and $C\left(z_{\mathrm{OZN} 2}\right)=0.7 \times 0.9-0.2 \times 0.8=0.47$. Since $C\left(z_{\mathrm{OZN} 1}\right)>C\left(z_{\mathrm{OZN} 2}\right)$, their sorting is $z_{\mathrm{OZN} 1}>z_{\mathrm{OZN} 2}$.

\section{Two Basic Aggregation Operators of OZNs}

This section presents two basic aggregation operators of OZNs based on the operations (7)-(9) in Definition 2 and their properties.

3.1. OZNWAM Operator. For a group of OZNs, the OZNWAM operator can be proposed from the operations (6) and (8) in Definition 2.
Definition 3. Set $z_{O Z N k}=\left\langle\left(T P_{k}, T Q_{k}\right),\left(F P_{k}, F Q_{k}\right)\right\rangle(k=1$, $2, \ldots, n)$ as a group of OZNs. Thus, the OZNWAM operator is defined below:

$$
\operatorname{OZNWAM}\left(z_{\mathrm{OZN1}}, z_{\mathrm{OZN2} 2}, \ldots, z_{\mathrm{OZNn}}\right)=\sum_{k=1}^{n} \alpha_{k} z_{\mathrm{OZNk}},
$$

where $\alpha_{k}(k=1,2, \ldots, n)$ is the weight of $z_{O Z N k}$ for $0 \leq \alpha_{k} \leq 1$ and $\sum_{k=1}^{n} \alpha_{k}=1$.

Theorem 1. Set $z_{\text {OZNk }}=\left\langle\left(T P_{k}, T Q_{k}\right),\left(F R_{k}, F M_{k}\right)\right\rangle(k=1$, $2, \ldots, n)$ as a group of OZNs. Thus, the aggregated value of the OZNWAM operator is still OZN, which is calculated by the following formula:

$$
\begin{aligned}
\mathrm{OZNWAM}\left(z_{\mathrm{OZN1}}, z_{\mathrm{OZN2} 2}, \ldots, z_{\mathrm{OZNn}}\right)= & \sum_{k=1}^{n} \alpha_{k} z_{\mathrm{OZNk}}=\left\langle\left(1-\prod_{k=1}^{n}\left(1-T P_{k}\right)^{\alpha_{k}}, 1-\prod_{k=1}^{n}\left(1-T Q_{k}\right)^{\alpha_{k}}\right),\right. \\
& \left.\cdot\left(\prod_{k=1}^{n} F P_{k}^{\alpha_{k}}, \prod_{k=1}^{n} F Q_{k}^{\alpha_{k}}\right)\right\rangle
\end{aligned}
$$

where $\alpha_{k}(k=1,2, \ldots, n)$ is the weight of $z_{\text {OZNk }}$ for $0 \leq \alpha_{k} \leq 1$ and $\sum_{k=1}^{n} \alpha_{k}=1$.
(1) Taking $n=2$, based on the operations (6) and (8) in Definition 2, one obtains the following result:

Proof. In terms of mathematical induction, equation (5) can be verified in the following way.

$$
\begin{aligned}
& \operatorname{OZNWAM}\left(z_{\mathrm{OZN1}}, z_{\mathrm{OZN} 2}\right)=\alpha_{1} z_{\mathrm{OZN1}} \oplus \alpha_{2} z_{\mathrm{OZN} 2} \\
& =\left\langle\begin{array}{c}
\left(1-\left(1-T P_{1}\right)^{\alpha_{1}}+1-\left(1-T P_{2}\right)^{\alpha_{2}}-\left(1-\left(1-T P_{1}\right)^{\alpha_{1}}\right)\left(1-\left(1-T P_{2}\right)^{\alpha_{2}}\right),\right. \\
\left.1-\left(1-T Q_{1}\right)^{\alpha_{1}}+1-\left(1-T Q_{2}\right)^{\alpha_{2}}-\left(1-\left(1-T Q_{1}\right)^{\alpha_{1}}\right)\left(1-\left(1-T Q_{2}\right)^{\alpha_{2}}\right)\right), \\
\left(F P_{1}^{\alpha_{1}} \cdot F P_{2}^{\alpha_{2}}, F Q_{1}^{\alpha_{1}} \cdot F Q_{2}^{\alpha_{2}}\right)
\end{array}\right\rangle \\
& =\left\langle\left(1-\prod_{k=1}^{2}\left(1-T P_{k}\right)^{\alpha_{k}}, 1-\prod_{k=1}^{2}\left(1-T Q_{k}\right)^{\alpha_{k}}\right),\left(\prod_{k=1}^{2} F P_{k}^{\alpha_{k}}, \prod_{k=1}^{2} F Q_{k}^{\alpha_{k}}\right)\right\rangle .
\end{aligned}
$$

(2) Taking $n=m$, equation (4) can keep the result:

$$
\begin{aligned}
\operatorname{OZNWAM}\left(z_{\mathrm{OZN1}}, z_{\mathrm{OZN2}}, \ldots, z_{\mathrm{OZNm}}\right)= & \sum_{k=1}^{m} \alpha_{k} z_{\mathrm{OZNk}}=\left\langle\left(1-\prod_{k=1}^{m}\left(1-T P_{k}\right)^{\alpha_{k}}, 1-\prod_{k=1}^{m}\left(1-T Q_{k}\right)^{\alpha_{k}}\right),\right. \\
& \left.\cdot\left(\prod_{k=1}^{m} F P_{k}^{\alpha_{k}}, \prod_{k=1}^{m} F Q_{k}^{\alpha_{k}}\right)\right\rangle .
\end{aligned}
$$

(3) Taking $n=m+1$, based on the operations (6) and (8) in Definition 2 and equations (6) and (7), one obtains the following result: 


$$
\begin{aligned}
\operatorname{OZNWAM}\left(z_{\mathrm{OZN1}}, z_{\mathrm{OZN2}}, \ldots, z_{\mathrm{OZNm}}, z_{\mathrm{OZN} m+1}\right)= & \sum_{k=1}^{m+1} \alpha_{k} z_{\mathrm{OZNk}}=\left\langle\left(1-\prod_{k=1}^{m}\left(1-T P_{k}\right)^{\alpha_{k}}, 1-\prod_{k=1}^{m}\left(1-T Q_{k}\right)^{\alpha_{k}}\right),\right. \\
& \left.\cdot\left(\prod_{k=1}^{m} F P_{k}^{\alpha_{k}}, \prod_{k=1}^{m} F Q_{k}^{\alpha_{k}}\right)\right\rangle \oplus \alpha_{m+1} z_{\mathrm{OZN} m+1} \\
= & \left\langle\left(1-\prod_{k=1}^{m+1}\left(1-T P_{k}\right)^{\alpha_{k}}, 1-\prod_{k=1}^{m+1}\left(1-T Q_{k}\right)^{\alpha_{k}}\right),\left(\prod_{k=1}^{m+1} F P_{k}^{\alpha_{k}}, \prod_{k=1}^{m+1} F Q_{k}^{\alpha_{k}}\right)\right\rangle .
\end{aligned}
$$

Regarding the above results, equation (5) can hold for any $n$.

Hence, the proof is completed.

Theorem 2. The OZNWAM operator of equation (5) implies the following properties: (a) Idempotency: set $z_{\mathrm{OZNk}}=\left\langle\left(T P_{k}, T Q_{k}\right),\left(F P_{k}, F Q_{k}\right)\right\rangle$ $(k=1,2, \ldots, n)$ as a group of OZNs. If $z_{\mathrm{OZNk}}=z_{\mathrm{OZN}}$ $(k=1, \quad 2, \quad \ldots, \quad n)$, thenOZNWAM $\left(z_{\mathrm{OZN1} 1}, z_{\mathrm{OZN2}}, \ldots, z_{\mathrm{OZNn}}\right)=z_{\mathrm{OZN}}$

(b) Boundedness: let $z_{O Z N k}=\left\langle\left(T P_{k}, T Q_{k}\right),\left(F P_{k}, F Q_{k}\right)\right\rangle$ $(k=1,2, \ldots, n)$ be a group of OZNs, and let the minimum and maximum OZNs be in the following:

$$
\begin{aligned}
& z_{\text {OZN min }}=\left\langle\left(\min _{k}\left(T P_{k}\right), \min _{k}\left(T Q_{k}\right)\right),\left(\max _{k}\left(F P_{k}\right), \max _{k}\left(F Q_{k}\right)\right)\right\rangle, \\
& z_{\text {OZN max }}=\left\langle\left(\max _{k}\left(T P_{k}\right), \max _{k}\left(T Q_{k}\right)\right),\left(\min _{k}\left(F P_{k}\right), \min _{k}\left(F Q_{k}\right)\right)\right\rangle .
\end{aligned}
$$

Thus, $z_{\mathrm{OZN} \min } \leq \mathrm{OZNWAM}\left(z_{\mathrm{OZN1}}, z_{\mathrm{OZN} 2}, \ldots\right.$, $\left.z_{\mathrm{OZNn}}\right) \leq z_{\mathrm{OZN} \max }$ can exist.

(c) Monotonicity: let $z_{\mathrm{OZNk}}=\left\langle\left(T P_{k}, T Q_{k}\right),\left(F P_{k}, F Q_{k}\right)\right\rangle$ and $z_{\mathrm{OZNk}}^{*}=\left\langle\left(T P_{k}^{*}, T Q_{k}^{*}\right),\left(F P_{k}^{*}, F Q_{k}^{*}\right)\right\rangle(k=1,2, \ldots$, $n)$ be two groups of OZNs. If $z_{O Z N j} \leq z_{O Z N j}^{*}$, then $\operatorname{OZNWAM}\left(z_{\mathrm{OZN1}}, z_{\mathrm{OZN2} 2}, \quad \ldots, \quad z_{\mathrm{OZNn}}\right)$ $\leq$ OZNWAM $\left(z_{\mathrm{OZN1}}^{*}, z_{\mathrm{OZN2}}^{*}, \ldots, z_{\mathrm{OZNn}}^{*}\right)$.

\section{Proof}

(a) When $z_{O Z N k}=z_{O Z N}(k=1,2, \ldots, n)$, one obtains the result of equation (5):

$$
\begin{aligned}
\operatorname{OZNWAM}\left(z_{\mathrm{OZN1}}, z_{\mathrm{OZN2}}, \ldots, z_{\mathrm{OZNn}}\right) & =\sum_{k=1}^{n} \alpha_{k} z_{\mathrm{OZNk}} \\
& =\left\langle\left(1-\prod_{k=1}^{n}\left(1-T P_{k}\right)^{\alpha_{j}}, 1-\prod_{k=1}^{n}\left(1-T Q_{k}\right)^{\alpha_{k}}\right),\left(\prod_{k=1}^{n} F P_{k}^{\alpha_{k}}, \prod_{k=1}^{n} F Q_{k}^{\alpha_{k}}\right)\right\rangle \\
& =\left\langle\left(1-(1-T P) \sum_{k=1}^{n} \alpha_{k}, 1-(1-T Q) \sum_{k=1}^{n} \alpha_{k}\right),\left(F P \sum_{k=1}^{n} \alpha_{k}, F Q \sum_{k=1}^{n} \alpha_{k}\right)\right\rangle \\
& =\langle(1-(1-T P), 1-(1-T Q)),(F P, F Q)\rangle \\
& =\langle(T P, T Q),(F P, F Q)\rangle=z_{O Z N} .
\end{aligned}
$$

(b) Since $z_{O Z N \min }$ and $z_{\mathrm{OZNmax}}$ are the minimum and the maximum OZNs, there is $z_{\text {OZNmin }} \leq z_{\text {OZN }} \leq z_{\text {OZNmax }}$. Hence, $\quad \sum_{k=1}^{n} \alpha_{k} z_{\text {OZN min }} \leq \sum_{k=1}^{n} \alpha_{k} z_{\text {OZN }} \leq \sum_{k=1}^{n}$ $\alpha_{k} z_{O Z N \max }$ can hold. Regarding the property (1), there exists $z_{O Z N \text { min }} \leq \sum_{k=1}^{n} \alpha_{k} z_{O Z N k} \leq z_{O Z N \text { max }}$, i.e., $z_{\mathrm{OZN} \text { min }} \leq \mathrm{OZNWAM}\left(z_{\mathrm{OZN1}}, z_{\mathrm{OZN} 2}, \ldots, z_{\mathrm{OZNn}}\right)$ $\leq z_{\text {OZN max }}$.

(c) If $z_{\text {OZNk }} \leq z_{\text {OZNk }}^{*}$, then $\sum_{k=1}^{n} \alpha_{k} z_{\text {OZNk }} \leq \sum_{k=1}^{n}$ $\alpha_{k} z_{\text {OZNk }}^{*}$, i.e., $\quad$ OZNWAM $\left(z_{\mathrm{OZN1} 1}, \quad z_{\mathrm{OZN2} 2}, \ldots\right.$, $\left.z_{\text {OZNn }}\right) \leq$ OZNWAM $\left(z_{O Z N 1}^{*}, z_{O Z N 2}^{*}, \ldots, z_{O Z N n}^{*}\right)$.
Hence, the proof of Theorem 2 is completed.

3.2. OZNWGM Operator. In this part, we can propose the OZNWGM operator according to the operations (7) and (9) in Definition 2.

Definition 4. Set $z_{\text {OZNk }}=\left\langle\left(T P_{k}, T Q_{k}\right),\left(F P_{k}, F Q_{k}\right)\right\rangle(k=1$, $2, \ldots, n)$ as a group of OZNs. Thus, the OZNWGM operator is defined below: 


$$
\operatorname{OZNWGM}\left(z_{\mathrm{OZN1}}, z_{\mathrm{OZN2}}, \ldots, z_{\mathrm{OZNn}}\right)=\prod_{k=1}^{n} z_{\mathrm{OZNk}}^{\alpha_{k}},
$$

where $\alpha_{k}(k=1,2, \ldots, n)$ is the weight of $z_{\text {OZNk }}$ for $0 \leq \alpha_{k} \leq 1$ and $\sum_{k=1}^{n} \alpha_{k}=1$.
Theorem 3. Set $z_{\text {OZNk }}=\left\langle\left(T P_{k}, T Q_{k}\right),\left(F P_{k}, F Q_{k}\right)\right\rangle(k=1$, $2, \ldots, n)$ as a group of OZNs. Thus, the aggregated value of the OZNWGM operator is still OZN, which is calculated by the following formula:

$$
\begin{aligned}
\operatorname{OZNWGM}\left(z_{\mathrm{OZN1}}, z_{\mathrm{OZN2}}, \ldots, z_{\mathrm{OZNn}}\right)= & \prod_{k=1}^{n} z_{\text {OZN }}^{\alpha_{k}}=\left\langle\left(\prod_{k=1}^{n} T P_{k}^{\alpha_{k}}, \prod_{k=1}^{n} T Q_{k}^{\alpha_{k}}\right),\right. \\
& \left.\cdot\left(1-\prod_{k=1}^{n}\left(1-F P_{k}\right)^{\alpha_{k}}, 1-\prod_{k=1}^{n}\left(1-F Q_{k}\right)^{\alpha_{k}}\right)\right\rangle,
\end{aligned}
$$

where $\alpha_{k}$ is the weight of $z_{\text {OZNk }}(k=1,2, \ldots, n)$ for $0 \leq \alpha_{k} \leq 1$ and $\sum_{k=1}^{n} \alpha_{k}=1$.

Similar to the proof process of Theorem 1, equation (12) can be also verified, which is omitted.

Theorem 4. The OZNWGM operator of equation (12) implies the following properties: (a) Idempotency: set $z_{O Z N k}=\left\langle\left(T P_{k}, T Q_{k}\right),\left(F P_{k}, F Q_{k}\right)\right\rangle$ $(j=1,2, \ldots, n)$ as a group of OZNs. If $z_{\mathrm{OZNk}}=z_{\mathrm{OZN}}$ $(k=1, \quad 2, \quad \ldots, \quad n)$, thenOZNWGM $\left(z_{\mathrm{OZN1}}, z_{\mathrm{OZN} 2}, \cdots, z_{\mathrm{OZNn}}\right)=z_{\mathrm{OZN}}$.

(b) Boundedness: set $z_{\mathrm{OZNk}}=\left\langle\left(T P_{k}, T Q_{k}\right),\left(F P_{k}, F Q_{k}\right)\right\rangle$ $(k=1,2, \ldots, n)$ as a group of OZNs and take the following minimum and maximum OZNs:

$$
\begin{aligned}
& z_{\text {OZN min }}=\left\langle\left(\min _{k}\left(T P_{k}\right), \min _{k}\left(T Q_{k}\right)\right),\left(\max _{k}\left(F P_{j}\right), \max _{k}\left(F Q_{k}\right)\right)\right\rangle, \\
& z_{\text {OZN max }}=\left\langle\left(\max _{k}\left(T P_{k}\right), \max _{k}\left(T Q_{k}\right)\right),\left(\min _{k}\left(F P_{k}\right), \min _{k}\left(F Q_{k}\right)\right)\right\rangle .
\end{aligned}
$$

Thus, there exists $z_{\mathrm{OZN} \text { min }} \leq \mathrm{OZNWGM}\left(z_{\mathrm{OZN1}}\right.$, $\left.z_{\mathrm{OZN2}}, \ldots, z_{\mathrm{OZNn}}\right) \leq z_{\mathrm{OZN} \max }$.

(c) Monotonicity: set $z_{\mathrm{OZNk}}=\left\langle\left(T P_{k}, T Q_{k}\right),\left(F P_{k}, F Q_{k}\right)\right\rangle$ and $z_{\mathrm{OZNk}}^{*}=\left\langle\left(T P_{k}^{*}, T Q_{k}^{*}\right),\left(F P_{k}^{*}, F Q_{k}^{*}\right)\right\rangle(k=1,2, \ldots$, $n)$ as two groups of OZNs. If $z_{\mathrm{OZNk}} \leq z_{\mathrm{OZNk}}^{*}$, then OZNWGM $\left(z_{\mathrm{OZN1} 1}, z_{\mathrm{OZN2}}, \quad \ldots, z_{\mathrm{OZNn}}\right) \leq \mathrm{OZNWGM}$ $\left(z_{\mathrm{OZN} 1}^{*}, z_{\mathrm{OZN} 2}^{*}, \ldots, z_{\mathrm{OZNn}}^{*}\right)$.

Clearly, the above properties of the OZNWGM operator can be also verified by the similar proof way of Theorem 2, which is omitted.

\section{MADM Model in terms of the Weighted Mean Operation of the OZNWAM and OZNWGM Operators}

This section establishes a MADM model corresponding to the weighted mean operation of the OZNWAM and
OZNWGM operators to perform MADM problems with the information of OZNs.

In a MADM problem, a set of alternatives $B=\left\{B_{1}, B_{2}, \ldots\right.$, $\left.B_{m}\right\}$ is provided and evaluated by a set of attributes $Y=\left\{y_{1}\right.$, $\left.y_{2}, \ldots, y_{n}\right\}$. Meanwhile, the impotence of each attribute $y_{k}$ $(k=1,2, \ldots, n)$ is specified by the weight $\alpha_{k}$. DMs are invited to assess the suitability of each alternative $B_{i}(i=1,2, \ldots, m)$ over the attributes $y_{k}(k=1,2, \ldots, n)$ by the truth and falsehood ZNs, which are constructed as the OZN $z_{\text {OZNik }}=$ $\left\langle\left(T P_{i k}, T Q_{i k}\right),\left(F P_{i k}, F Q_{i k}\right)\right\rangle$ for $T P_{i k}, T Q_{i k} \in[0,1], F P_{i k}$, $F Q_{i k} \in[0,1]$, and $0 \leq T P_{i k}+F P_{i k} \leq 1$. Then, the decision matrix of OZNs can be denoted by $Z_{O Z N}=\left(z_{\text {OZNik }}\right)_{m \times n}$. Thus, this MADM model is established and depicted by the following decision process:

Step 1: using equations (5) and (12), the aggregated OZNs $z_{\mathrm{OZN1} i}$ and $z_{\mathrm{OZN} 2 i}$ are calculated by the following formulae: 


$$
\begin{aligned}
z_{\text {OZN } 1 i} & =\operatorname{OZNWAM}\left(z_{\mathrm{OZNi1}}, z_{\mathrm{OZNi2}}, \ldots, z_{\mathrm{OZNin}}\right)=\sum_{k=1}^{n} \alpha_{k} z_{\mathrm{OZNik}} \\
& =\left\langle\left(1-\prod_{k=1}^{n}\left(1-T P_{i k}\right)^{\alpha_{k}}, 1-\prod_{k=1}^{n}\left(1-T Q_{i k}\right)^{\alpha_{k}}\right),\left(\prod_{k=1}^{n} F P_{i k}^{\alpha_{k}}, \prod_{k=1}^{n} F Q_{i k}^{\alpha_{k}}\right)\right\rangle, \\
z_{\mathrm{OZN} 2 i} & =\operatorname{OZNWGM}\left(z_{\mathrm{OZNi1}}, z_{\mathrm{OZNi2}}, \ldots, z_{\mathrm{OZNin}}\right) \\
& =\prod_{k=1}^{n} z_{\text {OZNik }}^{\alpha_{k}}\left\langle\left(\prod_{k=1}^{n} T P_{i k}^{\alpha_{k}}, \prod_{k=1}^{n} T Q_{i k}^{\alpha_{k}}\right),\left(1-\prod_{k=1}^{n}\left(1-F P_{i k}\right)^{\alpha_{k}}, 1-\prod_{k=1}^{n}\left(1-F Q_{i k}\right)^{\alpha_{k}}\right)\right\rangle .
\end{aligned}
$$

Step 2: the weighted mean operation of the OZNWAM and OZNWGM operators with the weights $\beta_{1}$ and $\beta_{2}=1-\beta_{1}$ for $\beta_{1} \in[0,1]$ is calculated by the following equation:

$$
\begin{aligned}
H_{\mathrm{OZN} i} & =\beta_{1} z_{\mathrm{OZN} 1 i} \oplus \beta_{2} z_{\mathrm{OZN} 2 i}=\beta_{1} z_{\mathrm{OZN} 1 i} \oplus\left(1-\beta_{1}\right) z_{\mathrm{OZN} 2 i} \\
& =\left\langle\left(1-\left(1-T P_{1 i}\right)^{\beta_{1}}\left(1-T P_{2 i}\right)^{1-\beta_{1}}, 1-\left(1-T Q_{1 i}\right)^{\beta_{1}}\left(1-T Q_{2 i}\right)^{1-\beta_{1}}\right),\left(F P_{1 i}^{\beta_{1}} \cdot F P_{2 i}^{1-\beta_{1}}, F Q_{1 i}^{\beta_{1}} \cdot F Q_{2 i}^{1-\beta_{1}}\right)\right\rangle .
\end{aligned}
$$

Step 3: the values of $C\left(H_{O Z N i}\right)\left(E\left(H_{O Z N i}\right)\right.$ if necessary) $(i=1,2, \ldots, m)$ are calculated by equation (2) (equation (3)).

Step 4: the alternatives are sorted in terms of the sorting rules, and the best one is chosen.

Step 5 : end.

\section{Example and Comparative Analysis}

5.1. Illustrative Example. Today, various robots have been used in industry, household services, and medical fields. They are changing our daily lives in various ways. Then, the performance evaluation of the robot is an important issue in the user's selection process. To illustrate the applicability of the presented MADM model in the case of OZNs, this section applies the proposed MADM model to the selection of industrial robots to illustrate its application in the case of OZNs.
An industrial company wants to purchase an industrial robot to improve its existing manufacturing system. The technical department initially considers four types of potential industrial robots (alternatives), which are denoted as a set $B=\left\{B_{1}, B_{2}, B_{3}, B_{4}\right\}$. To choose the most suitable one, they must satisfy four performance requirements (attributes): carrying capacity $\left(y_{1}\right)$, dexterity and work space $\left(y_{2}\right)$, operation accuracy $\left(y_{3}\right)$, and communication and control capabilities $\left(y_{4}\right)$. The weigh vector of the four attributes is specified by $\boldsymbol{\alpha}=(0.28,0.26,0.24,0.22)$. Thus, the experts/ DMs are invited to evaluate the four alternatives over the four attributes by OFVs and corresponding reliability levels, which are expressed as OZNs $z_{\text {OZNik }}=\left\langle\left(T P_{i k}, T Q_{i k}\right)\right.$, $\left.\left(F P_{i k}, F Q_{i k}\right)\right\rangle(i$ and $k=1,2,3$, and 4$)$ for $T P_{i k}, T Q_{i k} \in[0,1]$, $F P_{i k}, F Q_{i k} \in[0,1]$, and $0 \leq T P_{i k}+F P_{i k} \leq 1$. Thus, all OZNs can be constructed as their decision matrix:

$$
Z_{\text {OZN }}=\left(z_{\text {OZNik }}\right)_{4 \times 4}=\left[\begin{array}{llll}
\langle(0.7,0.8),(0.2,0.8)\rangle & \langle(0.7,0.7),(0.2,0.8)\rangle\langle(0.7,0.8),(0.2,0.9)\rangle\langle(0.7,0.8),(0.2,0.7)\rangle \\
\langle(0.8,0.7),(0.1,0.9)\rangle & \langle(0.7,0.8),(0.1,0.8)\rangle\langle(0.8,0.7),(0.1,0.8)\rangle\langle(0.7,0.7),(0.1,0.8)\rangle \\
\langle(0.7,0.7),(0.3,0.8)\rangle\langle(0.6,0.7),(0.2,0.7)\rangle\langle(0.7,0.9),(0.2,0.7)\rangle & \langle(0.7,0.9),(0.2,0.7)\rangle \\
\langle(0.8,0.8),(0.2,0.7)\rangle & \langle(0.6,0.9),(0.1,0.8)\rangle\langle(0.6,0.7),(0.3,0.8)\rangle\langle(0.7,0.7),(0.2,0.7)\rangle
\end{array}\right] .
$$

In this case, the presented MADM model can be used for this MADM example, and then, its decision process is described in the following:

Step 1: using equations (14) and (15), the aggregated OZNs $z_{O Z N 1 i}$ and $z_{O Z N 2 i}(i=1,2,3,4)$ are obtained below: $z_{\text {OZN11 }}=<(0.7000, \quad 0.7778), \quad(0.2000, \quad 0.7991)>$, $z_{\mathrm{OZN12}}=<(0.7570,0.7300),(0.1000,0.8268)>$,

$z_{\mathrm{OZN13}}=<(0.6767,0.8190),(0.2240,0.7267)>$, and $z_{\mathrm{OZN} 14}=<(0.6908,0.7987),(0.1841,0.7483)>$,

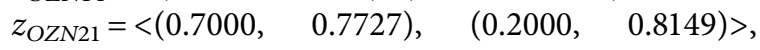
$z_{\text {OZN22 }}=<(0.7503,0.7247),(0.1000,0.8353)>$, 
TABLE 1: The decision results of the presented MADM model with the weight values of $\beta_{1}=0,0.5$, and 1 .

\begin{tabular}{lccc}
\hline Weight value & $C\left(z_{O Z N 1}\right), C\left(z_{O Z N 2}\right), C\left(z_{O Z N 3}\right), C\left(z_{O Z N 4}\right)$ & Sorting & The best one \\
\hline$\beta_{1}=0$ & $0.3779,0.4603,0.3605,0.3700$ & $B_{2}>B_{1}>B_{4}>B_{3}$ & $B_{2}$ \\
$\beta_{1}=0.5$ & $0.3813,0.4651,0.3764,0.3924$ & $B_{2}>B_{4}>B_{1}>B_{3}$ & $B_{2}$ \\
$\beta_{1}=1$ & $0.3846,0.4700,0.3914,0.4140$ & $B_{2}>B_{4}>B_{3}>B_{1}$ & $B_{2}$ \\
\hline
\end{tabular}

TABLe 2: Decision results regarding different MADM models.

\begin{tabular}{|c|c|c|c|}
\hline MADM model & Aggregated value & Score value & Sorting \\
\hline $\begin{array}{l}\text { Presented MADM } \\
\text { model with } \beta_{1}=1\end{array}$ & $\begin{array}{l}H_{O Z N 1}=<(0.7000,0.7778),(0.2000,0.7991)> \\
H_{O Z N 2}=<(0.7570,0.7300),(0.1000,0.8268)> \\
H_{O Z N 3}=<(0.6767,0.8190),(0.2240,0.7267)> \\
H_{O Z N 4}=<(0.6908,0.7987),(0.1841,0.7483)>\end{array}$ & $\begin{array}{l}C\left(H_{O Z N 1}\right)=0.3846 \\
C\left(H_{O Z N 2}\right)=0.4700 \\
C\left(H_{O Z N 3}\right)=0.3914 \\
C\left(H_{O Z N 4}\right)=0.4140\end{array}$ & $B_{2}>B_{4}>B_{3}>B_{1}$ \\
\hline $\begin{array}{l}\text { Presented MADM } \\
\text { method with } \beta_{1}=0.5\end{array}$ & $\begin{aligned} H_{O Z N 1} & =<(0.7000,0.7752),(0.2000,0.8069)> \\
H_{O Z N 2} & =<(0.7537,0.7274),(0.1000,0.8310)> \\
H_{O Z N 3} & =<(0.6746,0.8031),(0.2267,0.7294)> \\
H_{O Z N 4} & =<(0.6819,0.7875),(0.1924,0.7517)>\end{aligned}$ & $\begin{array}{l}C\left(H_{O Z N 1}\right)=0.3813 \\
C\left(H_{O Z N 2}\right)=0.4651 \\
C\left(H_{O Z N 3}\right)=0.3764 \\
C\left(H_{O Z N 4}\right)=0.3924\end{array}$ & $B_{2}>B_{4}>B_{1}>B_{3}$ \\
\hline Presented MADM method with $\beta_{1}=0$ & $\begin{aligned} H_{O Z N 1} & =<(0.7000,0.7727),(0.2000,0.8149)> \\
H_{O Z N 2} & =<(0.7503,0.7247),(0.1000,0.8353)> \\
H_{O Z N 3} & =<(0.6725,0.7858),(0.2294,0.7322)> \\
H_{O Z N 4} & =<(0.6728,0.7757),(0.2011,0.7551)>\end{aligned}$ & $\begin{array}{l}C\left(H_{O Z N 1}\right)=0.3779 \\
C\left(H_{O Z N 2}\right)=0.4603 \\
C\left(H_{O Z N 3}\right)=0.3605 \\
C\left(H_{O Z N 4}\right)=0.3700\end{array}$ & $B_{2}>B_{1}>B_{4}>B_{3}$ \\
\hline $\begin{array}{l}\text { Existing MADM model } \\
\text { using the IFNWAM operator [4] }\end{array}$ & $\begin{array}{l}z_{I F V 1}=<0.7000,0.2000> \\
z_{I F V 2}=<0.7570,0.1000> \\
z_{I F V 3}=<0.6767,0.2240> \\
z_{I F V 4}=<0.6908,0.1841>\end{array}$ & $\begin{array}{l}C\left(z_{I F V 1}\right)=0.5000 \\
C\left(z_{I F V 2}\right)=0.6570 \\
C\left(z_{I F V 3}\right)=0.4527 \\
C\left(z_{I F V 4}\right)=0.5067\end{array}$ & $B_{2}>B_{4}>B_{1}>B_{3}$ \\
\hline $\begin{array}{l}\text { Existing MADM method } \\
\text { using the IFNWGM operator [3] }\end{array}$ & $\begin{array}{l}z_{I F V 1}=<0.7000,0.2000> \\
z_{I F V 2}=<0.7503,0.1000> \\
z_{I F V 3}=<0.6725,0.2294> \\
z_{I F V 4}=<0.6728,0.2011>\end{array}$ & $\begin{array}{l}C\left(z_{I F V 1}\right)=0.5000 \\
C\left(z_{I F V 2}\right)=0.6503 \\
C\left(z_{I F V 3}\right)=0.4431 \\
C\left(z_{I F V 4}\right)=0.4716\end{array}$ & $B_{2}>B_{1}>B_{4}>B_{3}$ \\
\hline
\end{tabular}

$z_{\text {OZN23 }}=<(0.6725,0.7858),(0.2294,0.7322)>$, and $z_{\text {OZN24 }}=<(0.6728,0.7757),(0.2011,0.7551)>$

Step 2: using equation (16) with $\beta_{1}=0.5$, the values of $H_{\mathrm{OZN} i}$ are given below:

$$
\begin{aligned}
& H_{O Z N 1}=<(0.7000,0.7752), \quad(0.2000,0.8069)>, \\
& H_{O Z N 2}=<(0.7537,0.7274),(0.1000,0.8310)>, \\
& H_{O Z N 3}=<(0.6746,0.8031),(0.2267,0.7294)>\text {, and } \\
& H_{O Z N 4}=<(0.6819,0.7875),(0.1924,0.7517)>
\end{aligned}
$$

Step 3: by equation (2), the values of $C\left(H_{O Z N i}\right)$ for the alternatives $B_{i}(i=1,2,3$, and 4$)$ are obtained below:

$C\left(H_{O Z N 1}\right)=0.3813, \quad C\left(H_{O Z N 2}\right)=0.4651, \quad C\left(H_{O Z N 3}\right)=$ 0.3764 , and $C\left(H_{O Z N 4}\right)=0.3924$

Step 4: since $C\left(H_{O Z N 2}\right)>C\left(H_{O Z N 4}\right)>C\left(H_{O Z N 1}\right)$ $>C\left(H_{O Z N 3}\right)$, the sorting order of the four applicants is $B_{2}>B_{4}>B_{1}>B_{3}$. Hence, the best one is $B_{2}$.

To indicate the flexibility of the presented MADM model, we specify the weight values of $\beta_{1}=0,0.5$, and 1 .
Thus, the decision results of the presented MADM model are shown in Table 1.

Clearly, the sorting order of the alternatives in Table 1 changes with the change of the weight value of $\beta_{1}$, which verifies the decision-making flexibility. Then, the best selection is $B_{2}$. However, the choice of the weight value of $\beta_{1}$ depends on MD's preference and/or requirements of actual applications. Under normal circumstances, the weight value is generally taken as $\beta_{1}=0.5$ to reasonably make up for the prejudices of the two aggregation operators.

5.2. Comparative Analysis. For the convenience of comparative analysis with existing intuitionistic fuzzy MADM models $[3,4]$, if we ignore corresponding reliability levels and only consider IFVs in the decision matrix $Z_{\text {OZN }}=\left(z_{\text {OZNik }}\right)_{4 \times 4}$ as a special case of the above example, the decision matrix of OZNs degenerates into the decision matrix of IFVs:

$$
Z_{\text {IFN }}=\left(z_{\text {IFNik }}\right)_{4 \times 4}=\left[\begin{array}{cccc}
\langle 0.7,0.2\rangle & \langle 0.7,0.2\rangle & \langle 0.7,0.2\rangle & \langle 0.7,0.2\rangle \\
\langle 0.8,0.1\rangle & \langle 0.7,0.1\rangle & \langle 0.8,0.1\rangle & \langle 0.7,0.1\rangle \\
\langle 0.7,0.3\rangle & \langle 0.6,0.2\rangle & \langle 0.7,0.2\rangle & \langle 0.7,0.2\rangle \\
\langle 0.8,0.2\rangle & \langle 0.6,0.1\rangle & \langle 0.6,0.3\rangle & \langle 0.7,0.2\rangle
\end{array}\right],
$$


where $z_{\text {IFNik }}=\left\langle T P_{i k}, F P_{i k}\right\rangle(i$ and $k=1,2,3$, and 4$)$ are IFVs for $T P_{i k}, F P_{i k} \in[0,1]$ and $0 \leq T P_{i k}+F P_{i k} \leq 1$.

Thus, equations (14) and (15) and equations (2) and (3) also degenerate into existing IFV arithmetic mean
(IFVWAM) and IFV geometric mean (IFVWGM) operators and the score and accuracy functions of IFV $[3,4]$, respectively, below:

$$
\begin{gathered}
z_{I F V i}=I F V W A M\left(z_{I F V i 1}, z_{I F V i 2}, \ldots, z_{I F V i n}\right)=\left\langle 1-\prod_{k=1}^{n}\left(1-T P_{i k}\right)^{\alpha_{k}}, \prod_{k=1}^{n} F P_{i k}^{\alpha_{k}}\right\rangle, \\
z_{I F V i}=I F V W G M\left(z_{I F V i 1}, z_{I F V i 2}, \ldots, z_{I F V i n}\right)=\left\langle\prod_{k=1}^{n} T P_{i k}^{\alpha_{k}}, 1-\prod_{k=1}^{n}\left(1-F P_{i k}\right)^{\alpha_{k}}\right\rangle, \\
C\left(z_{I F V i}\right)=T P_{i}-F P_{i} \text { for } C\left(z_{I F V i}\right) \in[-1,1], \\
E\left(z_{I F V i}\right)=T P_{i}+F P_{i} \text { for } E\left(z_{I F V i}\right) \in[0,1] .
\end{gathered}
$$

Using equations (19)-(22), the decision results obtained by the existing intuitionistic fuzzy MADM models $[3,4]$ are shown in Table 2 . Then, the decision results obtained by the presented MADM model are also shown in Table 2.

In Table 2, there is the sorting difference between existing MADM models [3,4] since there are different prejudices between the IFNWAM operator and the IFNWGM operator. Then, the presented MADM model can make up for the flaw. Meanwhile, the presented MADM model with different weight values of $\beta_{1}$ can lead to different sorting orders, which demonstrates the flexible decision-making advantage, while the existing MADM models $[3,4]$ lack this flexibility. Especially, when $\beta_{1}=1$, the sorting order of the presented MADM model using the unique OZNWAM operator, which is a special case of the presented MADM model, is different from the sorting orders of the existing MADM models [3, 4], which shows that the reliability measure information can affect the sorting order. However, the presented MADM model shows the importance and efficiency of the reliability measures and weight values of $\beta_{1}$ in the MADM process. Then, the existing intuitionistic fuzzy MADM models $[3,4]$ only use the assessment information of the IFVs and the single aggregation operator, so they lack the reliability and flexibility of decision-making in the case of IFVs. Furthermore, the existing MADM models in the case of IFVs are only the special cases of the proposed MADM model and cannot perform MADM problems in the case of OZNs. Comparative analysis indicates that the presented MADM model can contain more advantages than the existing MADM models $[3,4]$ in the reliability and flexibility of decision results.

\section{Conclusion}

In terms of the notion of truth and falsehood ZNs, the proposed OZN set can enhance the reliability measures of OFVs. Then, the presented score and accuracy functions of OZNs and weighted mean operation of the OZNWAM and OZNWGM operators provided reasonable modeling tools for MADM issues in the case of OZN sets. The established MADM model using the weighted mean operation of the OZNWAM and OZNWGM operators and score and accuracy functions solved such a flexible MADM problem with OZN information. Through an illustrative example and comparison with the existing MADM models, the presented MADM model indicated more advantages than the existing MADM models in the decision-making reliability and flexibility. In the application of the presented MADM model, different weight values of $\beta_{1}$ can affect different sorting orders of alternatives and show some sensitivity to $\beta_{1}$. Therefore, the presented MADM model with different weight values of $\beta_{1}$ can satisfy the decision makers' preference selection regarding some specified decision result and/or requirement of actual applications in uncertain and incomplete cases. Furthermore, the presented MADM model can overcome the flaw of using the single aggregation operator (either the OZNWAM operator or OZNWGM operator) and make up for the prejudices of both. Generally, the superiority of this study is that the presented MADM model not only strengthens the reliability level of OFVs but also makes the decision results more reliable and flexible than existing methods $[3,4,24,25,28]$.

However, the original research has contributed to the expression of OZN, the weighted average operation of the two OZN aggregation operators, and the MADM model with OZN information, but they cannot express and deal with decision-making problems with inconsistent and indeterminate information, which shows their limitations. In the future study, we shall further propose other aggregation operators and similarity measures of OZNs and apply them in pattern recognition, medical diagnosis/assessment, group decision modeling, etc.

\section{Data Availability}

The data used to support the findings of this study are included within this article. 


\section{Conflicts of Interest}

The authors declare that they have no conflicts of interest.

\section{References}

[1] L. A. Zadeh, "Fuzzy sets," Information and Control, vol. 8, no. 5, pp. 338-353, 1965.

[2] K. T. Atanassov, "Intuitionistic fuzzy sets," Fuzzy Sets and Systems, vol. 20, no. 1, pp. 87-96, 1986.

[3] Z. Xu and R. R. Yager, "Some geometric aggregation operators based on intuitionistic fuzzy sets," International Journal of General Systems, vol. 35, no. 4, pp. 417-433, 2006.

[4] Z. S. Zeshui Xu, "Intuitionistic fuzzy aggregation operators," IEEE Transactions on Fuzzy Systems, vol. 15, no. 6, pp. 1179-1187, 2007.

[5] Y. Xu and H. Wang, "The induced generalized aggregation operators for intuitionistic fuzzy sets and their application in group decision making," Applied Soft Computing, vol. 12, no. 3, pp. 1168-1179, 2012.

[6] X. Yu and $\mathrm{Z} . \mathrm{Xu}$, "Prioritized intuitionistic fuzzy aggregation operators," Information Fusion, vol. 14, no. 1, pp. 108-116, 2013.

[7] X. Zhao and G. Wei, "Some intuitionistic fuzzy Einstein hybrid aggregation operators and their application to multiple attribute decision making," Knowledge-Based Systems, vol. 37, pp. 472-479, 2013.

[8] H. Garg, "Some series of intuitionistic fuzzy interactive averaging aggregation operators," SpringerPlus, vol. 5, no. 1, 2016.

[9] Z. Lu and J. Ye, "Decision-making method for clay-brick selection based on subtraction operational aggregation operators of intuitionistic fuzzy values," The Open Cybernetics \& Systemics Journal, vol. 10, no. 1, pp. 283-291, 2016.

[10] S.-M. Chen, S.-H. Cheng, and W.-H. Tsai, "Multiple attribute group decision making based on interval-valued intuitionistic fuzzy aggregation operators and transformation techniques of interval-valued intuitionistic fuzzy values," Information Sciences, vol. 367, pp. 418-442, 2016.

[11] S. M. Chen, S. H. Cheng, and W. H. Tsai, "A novel multiple attribute decision making method based on interval-valued intuitionistic fuzzy geometric averaging operators," in Proceedings of the Eighth International Conference on Advanced Computational Intelligence, pp. 79-83, Chiang Mai, Thailand, February 2016.

[12] P. Liu and S.-M. Chen, "Group decision making based on Heronian aggregation operators of intuitionistic fuzzy numbers," IEEE Transactions on Cybernetics, vol. 47, no. 9, pp. 2514-2530, 2017.

[13] J. Ye, "Intuitionistic fuzzy hybrid arithmetic and geometric aggregation operators for the decision-making of mechanical design schemes," Applied Intelligence, vol. 47, no. 3, pp. 743-751, 2017.

[14] P. Liu, J. Liu, and S.-M. Chen, "Some intuitionistic fuzzy Dombi Bonferroni mean operators and their application to multi-attribute group decision making," Journal of the Operational Research Society, vol. 69, no. 1, pp. 1-24, 2018.

[15] Z. Liu and F. Xiao, "An evidential aggregation method of intuitionistic fuzzy sets based on belief entropy," IEEE Access, vol. 7, pp. 68905-68916, 2019.

[16] R. R. Yager, "Pythagorean fuzzy subsets," in Proceedings of the Joint IFSA World Congress and NAFIPS Annual Meeting, pp. 57-61, Edmonton, Canada, November 2013.
[17] R. R. Yager, "Pythagorean membership grades in multicriteria decision making," IEEE Transactions on Fuzzy Systems, vol. 22, no. 4, pp. 958-965, 2014.

[18] S. Z. Zeng, J. P. Chen, and X. S. Li, "A hybrid method for Pythagorean fuzzy multiple-criteria decision making," International Journal of Information Technology and Decision Making, vol. 15, no. 2, pp. 403-422, 2016.

[19] K. Rahman, A. Ali, M. Shakeel, M. S. A. Khan, and M. Ullah, "Pythagorean fuzzy weighted averaging aggregation operator and its application to decision making theory," The Nucleus, vol. 54, no. 3, pp. 190-196, 2017.

[20] D. Liang, Y. Zhang, Z. Xu, and A. P. Darko, "Pythagorean fuzzy Bonferroni mean aggregation operator and its accelerative calculating algorithm with the multithreading," International Journal of Intelligent Systems, vol. 33, no. 3, pp. 615-633, 2018.

[21] Y. Xing, R. Zhang, J. Wang, and X. Zhu, "Some new pythagorean fuzzy choquet-frank aggregation operators for multi-attribute decision making," International Journal of Intelligent Systems, vol. 33, no. 11, pp. 2189-2215, 2018.

[22] M. Akram, W. A. Dudek, and J. M. Dar, "Pythagorean Dombi fuzzy aggregation operators with application in multicriteria decision-making," International Journal of Intelligent Systems, vol. 34, no. 11, pp. 3000-3019, 2019.

[23] F. Khan, M. S. A. Khan, M. Shahzad, and S. Abdullah, "Pythagorean cubic fuzzy aggregation operators and their application to multi-criteria decision making problems," Journal of Intelligent and Fuzzy Systems, vol. 36, no. 1, pp. 595-607, 2019.

[24] M. Akram, S. Alsulami, and K. Zahid, "A hybrid method for complex Pythagorean fuzzy decision making," Mathematical Problems in Engineering, vol. 2021, Article ID 9915432, 23 pages, 2021.

[25] A. Luqman, M. Akram, and J. C. R. Alcantud, "Digraph and matrix approach for risk evaluations under Pythagorean fuzzy information," Expert Systems with Applications, vol. 170, Article ID 114518, 2021.

[26] R. R. Yager and N. Alajlan, "Approximate reasoning with generalized orthopair fuzzy sets," Information Fusion, vol. 38, pp. 65-73, 2017.

[27] R. R. Yager, N. Alajlan, and Y. Bazi, "Aspects of generalized orthopair fuzzy sets," International Journal of Intelligent Systems, vol. 33, no. 11, pp. 2154-2174, 2018.

[28] F. Feng, Y. Zheng, B. Sun, and M. Akram, "Novel score functions of generalized orthopair fuzzy membership grades with application to multiple attribute decision making," Granular Computing, vol. 162, 2021.

[29] P. Liu and P. Wang, "Some q-rung orthopair fuzzy aggregation operators and their applications to multiple-attribute decision making," International Journal of Intelligent Systems, vol. 33, no. 2, pp. 259-280, 2018.

[30] P. Liu and J. Liu, "Someq-rung orthopai fuzzy bonferroni mean operators and their application to multi-attribute group decision making," International Journal of Intelligent Systems, vol. 33, no. 2, pp. 315-347, 2018.

[31] P. Liu and P. Wang, "Multiple-attribute decision-making based on Archimedean Bonferroni operators of q-rung orthopair fuzzy numbers," IEEE Transactions on Fuzzy Systems, vol. 27, no. 5, pp. 834-848, 2019.

[32] S. Naz, M. Akram, S. Alsulami, and F. Ziaa, "Decision-making analysis under interval-valued q-rung orthopair dual hesitant fuzzy environment," International Journal of Computational Intelligence Systems, vol. 14, no. 1, pp. 332-357, 2021. 
[33] J. Ye, S. Du, and R. Yong, "Orthopair indeterminate information expression, aggregations and multiattribute decision making method with indeterminate ranges," Journal of Control and Decision, vol. 13, pp. 1-9, 2021.

[34] L. A. Zadeh, "A note on Z-numbers," Information Sciences, vol. 181, no. 14, pp. 2923-2932, 2011.

[35] W. Jiang, C. Xie, M. Zhuang, Y. Shou, and Y. Tang, "Sensor data fusion with $Z$-numbers and its application in fault diagnosis," Sensors, vol. 16, no. 9, pp. 1-22, 2016.

[36] B. Kang, Y. Hu, Y. Deng, and D. Zhou, "A new methodology of multicriteria decision-making in supplier selection based onZ-numbers," Mathematical Problems in Engineering, vol. 2016, Article ID 8475987, 17 pages, 2016.

[37] B. Kang, G. Chhipi-Shrestha, Y. Deng, K. Hewage, and R. Sadiq, "Stable strategies analysis based on the utility of $Z$ number in the evolutionary games," Applied Mathematics and Computation, vol. 324, pp. 202-217, 2018. 